\title{
DETERMINAÇÃO DE PARÂMETROS DE BIOQUÍMICA SÉRICA EM LOBOS GUARÁ \\ (Chrysocyon brachyurus)
}

R. LOCATELLI-DITTRICH ${ }^{1}$; E.M.S. SCHMIDT ${ }^{2}$; G.C. PENSO ${ }^{3}$; R.M.V. MANGRICH ${ }^{4}$; S.F.C. SILVA ${ }^{5}$; M.E. SAITO ${ }^{6}$; G.P. PERAZZOLI ${ }^{7}$; A.S.M. PASSERINO ${ }^{8}$;

${ }^{1}$ Professores do Departamento de Medicina Veterinária - Universidade Federal do Paraná. ${ }^{2}$ Acadêmicas do Curso de Medicina Veterinária - Universidade Federal do Paraná. ${ }^{3}$ Aluna do Curso de Pós-Graduação em Biologia Celular Universidade Federal do Paraná. ${ }^{4}$ Professora de Doenças Infecciosas da UNIPAR/Umuarama - PR. ${ }^{5}$ Professora do Departamento de Medicina Veterinária - Universidade Federal do Paraná.

O lobo-guará é um canídeo sul americano, que está incluido na lista oficial de animais protegidos no Brasil pelo IBAMA e também recebe proteção de um programa de conservação mundial do WWF. Existem vários estudos sobre o comportamento social e manejo do lobo-guará, sendo escassas as informações referentes aos valores de bioquímica sérica destes animais. Neste estudo, objetivou-se estabelecer parâmetros bioquímicos séricos de uréia, creatinina, glicose, aspartato aminotransferase (AST), alanina aminotransferase (ALT), creatina fosfoquinase (CK), proteínas totais, albumina, amilase, cálcio, fósforo, magnésio e cloretos. Foram analisadas amostras de sangue (em triplicata) de oito exemplares adultos de loboguará, dois machos e seis fêmeas pertencentes ao plantel do Zoológico da Prefeitura Municipal de Curitiba. Utilizou-se a contenção física para a obtenção das amostras que foram colhidas pela punção da veia cefálica. As amostras foram acondicionadas em tubos sem anticoagulante e, posteriormente enviadas ao Laboratório de Análises Clínicas do Hospital Veterinário da UFPR. Os parâmetros bioquímicos foram determinados com auxílio de kits comerciais (Bioclin®) e leituras espectrofotométricas. As médias e os desvios padrão encontrados foram: uréia $(\mathrm{mg} / \mathrm{dl}) \rightarrow 60,4$ e 15,$9 ; \mathrm{creatinina}(\mathrm{mg} / \mathrm{dl}) \rightarrow$ 1,1 e 0,$3 ;$ glicose $(\mathrm{mg} / \mathrm{dl}) \rightarrow 70,4$ e 12,5 ; AST $(\mathrm{U} / \mathrm{l}) \rightarrow 34,9$ e 19,$5 ;$ ALT $(\mathrm{U} / \mathrm{l}) \rightarrow 27,0$ e 9,0; CK (U/l) $\rightarrow 213,8$ e 172,5; proteínas totais $(\mathrm{g} / \mathrm{dl}) \rightarrow 6,3$ e 0,9 ; albumina $(\mathrm{g} / \mathrm{dl}) \rightarrow 3,3$ e 0,4 ; amilase $(\mathrm{mg} / \mathrm{dl}) \rightarrow 230,4$ e 122,4 ; cálcio $(\mathrm{mg} / \mathrm{dl}) \rightarrow 9,8$ e 2,5 ; fósforo $(\mathrm{mg} / \mathrm{dl}) \rightarrow 7,3$ e 2,1 ; magnésio $(\mathrm{mg} / \mathrm{dl}) \rightarrow 3,5$ e 0,$8 ;$ cloretos $(\mathrm{mEq} / \mathrm{l}) \rightarrow 123,1$ e 4,5. Os valores de referência possibilitam uma avaliação clínica segura dos animais doentes, contribuindo para o conhecimento e a conservação das espécies selvagens. 